\title{
Optimal Forest Stock Determination in Côte d'Ivoire, in a Sustainable Development Perspective
}

\author{
Noufou Coulibaly \\ Management and Applied Economics Department, Institut National Polytechnique Houphouët Boigny, Yamoussoukro, Côte d'Ivoire

\section{Email address:} \\ noufou_coulibaly@yahoo.fr

\section{To cite this article:} \\ Noufou Coulibaly. Optimal Forest Stock Determination in Côte d'Ivoire, in a Sustainable Development Perspective. American Journal of \\ Environmental Protection. Vol. 5, No. 6, 2016, pp. 157-167. doi: 10.11648/j.ajep.20160506.13
}

Received: October 8, 2016; Accepted: November 1, 2016; Published: December 12, 2016

\begin{abstract}
For several decades, the forest sector in Cote d'Ivoire has undergone a drastic decrease of its forest coverage from $10,860,000$ ha in 1960 to $1,500,000$ ha in 2016. This situation brought about some climatic changes that affect farmers' traditional mode of production. The situation also has affected the wood industry through the lack of raw material (timber), forcing them fire workers. The objective of this study was, to determine the necessary size of the forest stock to preserve in order to maintain the ecological balance of the country. This equilibrium will allow the improvement of farming conditions (increased rainfall and climatic stability), revenue from farmers, the wood industry, and in return, the economy of the country. The results of this study indicate that, the forest stock for an ecological equilibrium in Cote d'Ivoire was estimated, at $8,343,000$ ha but that equilibrium was disrupted since 1978. To rebuild the forest coverage capital, the size of the reforestation should be between 99,000 and 500,000 ha of forest per year compared with, the real reforestation by the government from 2,000 to 7,000 ha per year. Given the high cost of reforestation, our study suggested a paid community reforestation that is more efficient and less expensive. The determination of these references (optimum forest stock for an ecological equilibrium and optimum reforestation) would help the government adjust its resources for future forest recovery projects in order to significantly revitalize the agriculture and forest sector, which is the main pillar of the country's economy and the principal jobs provider. One advantage of this strategy will be to considerably reduce the rural exodus.
\end{abstract}

Keywords: Optimal Management, Optimal Forest Stock, Sustainable Economic Growth

\section{Introduction}

Recently, the management of natural resources has been the main issue in the environment concerns. A sustainable economy, compatible with long-term objectives on the environment protection, such as the preservation of natural resources for the next generations, suggests an efficient management of the resources. The policies on natural resource management are meant to enrich and save the natural heritage, especially leisure sites provided by the protected natural regions [1]. A rational use of the resources allows not only a sustainable production of the specific resource but also its continuation without any negative externalities. This explains why the analysis of the problem regarding natural resources and the economic incentives are supported by the idea that the optimal social use of the resources is a key factor of a viable economic development process [2]. Therefore, this is the main idea on which our study of forestlands in Côte d'Ivoire is based.

The problem of the forest sector in Côte d'Ivoire has been no less than extremely preoccupying lately. In fact, the demographic expansion and the substantial economic development that the country has witnessed from 1960 to 2016, specifically in the agriculture sector, have as consequence an increasing pressure on the forestry sector. The size of the forest in Côte d'Ivoire has considerably decreased, from $10,860,000$ ha in 1960 to about 1.500 .000 ha in 2016 , corresponding to a degree of reforestation of about $2.6 \%$ for that period, leading the country to an ecological deadlock (climatic changes and reduction of the rainfall) with the effects being already perceptible. Given the complexity of the problems related to the decrease of the forest coverage and considering the importance of agricultural and forest use in the country's economy ( $33 \%$ of the GDP), we think that the answers to these problems should include a planning of 
an efficient use of the forestlands. Doing so, leads us to ask the following questions:

- What is the forest stock for an ecological balance?

- What is the level of reforestation that can help to achieve this balance stock?

- Which strategies to restore the ecological balance?

The objective of this study is to analyze the optimal management conditions for a sustainable development of the forest coverage in Côte d'Ivoire. Specifically this will imply:

a) Determining the optimal areas of forestland that should be allocated to forest related activities;

b) Explaining the difference between optimal forestland areas and the situation observed in the field;

c) Proposing a strategy to achieve this optimal allocation (new balance) in case that the observed areas were different than those determined.

d) choosing the economic approach underpinned by a mathematical method of dynamic optimization, namely linear programming Model,

\section{Literature Review}

Several tools in the context of the rational management of resources are used to help policy makers to take good decision. These tools can be presented as mentioned below.

The analysis of the effects of inappropriate use of the resources is made possible [1]., by the use of two related concepts that are: the Collective Cost of Opportunity (CCO) of resource use which is bound with the optimal rate in which a resource should be used. It includes three elements which are: the direct costs of extraction or harvesting $(\mathrm{Ch})$, the costs that the user imposes to the future users $(\mathrm{Cu})$ and, the external costs $(\mathrm{Ce})$ bound to the resource use. What summarizes as: $\mathrm{CCO}=\mathrm{Ch}+\mathrm{Cu}+\mathrm{Ce}$; and, the Total Economic Value (TEV), which refers to the components of sustainable resource conservation; and includes: the consumption value $(\mathrm{Bc})$, the value for future users or option value (Bo), and the value that the resource takes in sustainable preservation condition or the existence value $(\mathrm{Be})$, which is summarized as follows: $\mathrm{TEV}=\mathrm{Bc}+\mathrm{Bo}+\mathrm{Be}$.

The CCO highlights the profit-cost analytical method in the management of natural resources [1]. Indeed, the inclusion of environment-related costs in the national accounts as well as the assessment and the monitoring of natural resources are management tools of natural resources according to reference [3].

There is a strong demand for forest products. Unlike the vast array of goods produced by the economy, private markets mechanisms have failed to solve the allocation problem with regard to multiple use services. Whatever the demand, multiple use evaluation is as much a matter of institutional form as economic method. Among the methods which may be used within a given institutional framework are: Money (Dollar) value reference points, opportunity cost, shadow prices, interagency bargaining, artificial markets and programming [4].

The mathematical models contributed to the management of natural resources and have been applied in several studies particularly on econometric models, in determining the causes of deforestation. These models have two gaps in the inability to overcome explicitly and implicitly the definition of forest and deforestation on the one hand; and secondly, to highlight the explanatory variables and the burden of responsibility in deforestation. That is why, according to these same authors, econometrics loses its relevance in favor of general equilibrium models and optimization models [5].

As for the general equilibrium model used on 1996 [6], it also loses its acuteness because of the difficulty in modeling the behavior of actors across parameters as elasticities and the propensity to save. Thus, authors come to condemn the use of CGE models for policy evaluation.

While McConnell [7], reveals that the problem of effective and optimal use of resources can be solved as a profit maximization problem from different uses of this resource by the use of optimization mathematical models. Thus the author has developed a programming model to three types of land use (agriculture, urban planning, and forestry). It was followed by the study on forest land in Côte d'Ivoire through optimal control model [8]. Optimization models are presented generally as follows:

Max Z: $\Sigma$ bij. Xj, which is the objective function to be maximized;

Subject to constraints functions:

$$
\begin{gathered}
\text { Eaij.Xj } \leq \text { Es } \\
X j \geq 0
\end{gathered}
$$

In our study, we chose the last method (mathematical optimization model), including dynamic programming method for reasons of strength, which are presented in the following section.

\section{Method}

In order to suite to the objectives of this study, the methodology we used consisted in:

- Modeling the forestland use in a form of mathematic equation that included all variables needed for its resolution.

- Defining three groups of scenarios that depend on two parameters, the forest value and the social discount rate, in order to undertake a parameterization. The forest could have values of: $10 \mathrm{USD}, 50 \mathrm{USD}, 70 \mathrm{USD}$, and 112 USD per ha. The value represents the total fees and donations to possess a hectare of forestland, depending on the region and the relative functions. The social discount rates were: $3 \%, 5 \%, 7 \%$, and $10 \%$ (values of the international and the Central Bank of West African States- BCEAO loan interest rates). The scenario 1 (scenario maximum) results from the combination of maximum income and maximum social discount rate; the scenario 2 (scenario intermediary) results from the combination of average income and intermediary social discount rate; and the scenario 3 (scenario minimum) results from the combination of minimum 
revenue and minimum social discount rate.

- Estimating the agricultural and forest average incomes per ha of land from 1960 to 2016, which were previously deflated compared to the consumer price index (1985 basis).

- Running the models with the General Algebraic Modeling System (GAMS) software.

Our primary and secondary data were collected from surveys conducted with farmers, administrative and political officials, State departments (Agriculture and rural development, Animals and Fisheries Production, Environment, Economic and Finance) research, National Agronomy Research Center (CNRA) and development structures (Ivorian State Company for Forest Development, National Bureau of Technical and Development Studies) institutes, and/or World Bank institutes. The study area is the forest region of the country represented in green in Figure 1.

\section{Carte de base de la cobte d'Ivolre}

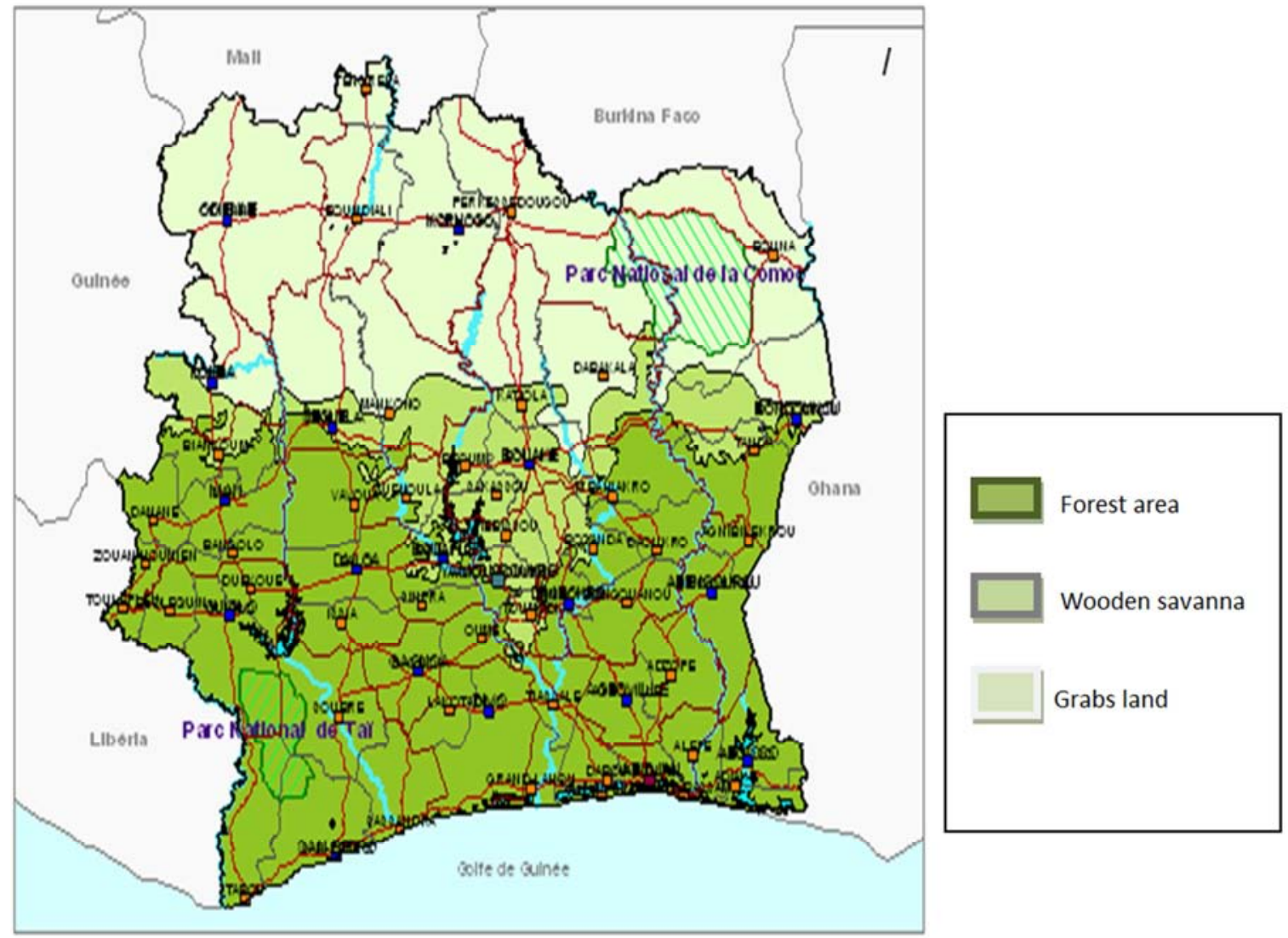

Figure 1. Forest situation in Côte d'Ivoire, 1900 [9].

The model is written as follows:

$$
\operatorname{Max} \mathrm{Z}=\sum_{\mathrm{T}}^{1960-2016}((1 /(1+\mathrm{R} 0) \mathrm{T}) *(\mathrm{RF}(\mathrm{T}) * \mathrm{D}(\mathrm{T})+\mathrm{RA}(\mathrm{T}) * \mathrm{SA}(\mathrm{T})-0.30 * \mathrm{RF}(\mathrm{T}) * \mathrm{SR}(\mathrm{T})+\mathrm{Fv} * \mathrm{FO}(\mathrm{T}) *(1+\mathrm{R} 0) \mathrm{T})
$$

Subject to:

$$
\begin{array}{r}
\mathrm{D}(\mathrm{T})+\mathrm{SA}(\mathrm{T})+\mathrm{SR}(\mathrm{T})+\mathrm{FO}(\mathrm{T})=\mathrm{W} *(1 /(1+0.005) \mathrm{T}) \\
\mathrm{FO}(\mathrm{T})+\mathrm{SR}(\mathrm{T})>=0.20 * \mathrm{~W}(\mathrm{~T}) \\
\mathrm{SA}(\mathrm{T})>=0.8 \mathrm{SA}(\mathrm{T}-1)+0.40 \mathrm{D}(\mathrm{T}-1) \\
\mathrm{FO}(\mathrm{T})>=0.15 \mathrm{D}(\mathrm{T}-1)+\mathrm{SR}(\mathrm{T}-1)+\mathrm{FO}(\mathrm{T}-1) \\
\mathrm{D}(\mathrm{T})>=\mathrm{D}(\mathrm{T}-1) *(1+\mathrm{R} 7(\mathrm{~T})) \mathrm{T} \\
\mathrm{D}(\mathrm{T}), \mathrm{SA}(\mathrm{T}), \mathrm{SR}(\mathrm{T}), \mathrm{FO}(\mathrm{T})>=0
\end{array}
$$

Where:

- $\mathrm{Z}$ is the sum of income from different land use

- $\mathrm{SA}(\mathrm{T})$ is the agricultural area at each instant.
- $\mathrm{D}(\mathrm{T})$ is the forestry (forest activities) area at each instant.

- $\mathrm{SR}(\mathrm{T})$ is the reforested area at each instant.

- $\mathrm{FO}(\mathrm{T})$ is the stock of forest area at each instant.

- $\mathrm{R} 7(\mathrm{~T})$ is the annual deforestation growth rate.

- $\mathrm{R}_{0}$ is the social discount rate (the interest rate of the society).

- Fv is the value of the forest.

- $\mathrm{RF}(\mathrm{T})$ is the income per ha of used forest.

- RA(T) is the agricultural income per ha.

- $\mathrm{T}$ indicates that the parameters are function of time.

The equation (1) represented the total value or the sum of instant values from different uses of the land, from 1960 to 2016, where: 
- $\left(1 /\left(1+\mathrm{R}_{0}\right)^{\mathrm{T}}\right.$ represents the factor of discount values.

- $\mathrm{RF}(\mathrm{T})^{*} \mathrm{D}(\mathrm{T})$ represents the instant income from forestry areas (harvest timber).

- $\mathrm{RA}(\mathrm{T}) * \mathrm{SA}(\mathrm{T})$ represents the instant income from agricultural activities.

- $0.30 * \mathrm{RF}(\mathrm{T}) * \mathrm{SR}(\mathrm{T})$ represents the estimated cost of instant reforestation activities, according to our surveys, considering the lack of transparence around the real values of these activities. In fact the unit cost of the reforestation is estimated at 1200 to 1600 USD per ha, according to the "Department in charge of Forest development in Côte d'Ivoire" (SODEFOR). This cost was overestimated because its setting took in account many factors that had no direct link to reforestation. To avoid this ambiguity, we used a survey to estimate the cost based on the income from one hectare of private forest.

- $\mathrm{FV}^{*} \mathrm{FO} *\left(1 /\left(1+\mathrm{R}_{0}\right)^{\mathrm{T}}\right.$ is the instant value capitalized with the social discount rate.

The other remaining equations are restrictions factors that are interpreted as follows:

Equation (2) stipulated that the sum of land allocated to different activities (agriculture, forest use or timber harvest, reforestation, forest stock) should always equal the total quantity of forest available at a given time. According to reference [10], $0.5 \%$ of lands are lost each year in the form of soil erosion or as urbanization effect.

Equation (3) indicated that the forest stock at a given time must be at least greater than $20 \%$ of the initial quantity of land forests, and this in order to preserve the amount of biophysical environment [11]. This supports the idea that a country must have as objective at least a $20 \%$ of forest coverage from its territory.

Equation (4) indicated that the cultivated forest area each year, is at least equal $80 \%$ of the previous year forest area cultivated increased with $40 \%$ as the current year deforested surfaces. In fact, our surveys indicated that each year farmers reuse $80 \%$ of their lands and seek new naturally fertile forestlands estimated to be $40 \%$. This is what is translated in our equation (4).

Equation (5) indicated the level of forest stock represented by the regeneration of $15 \%$ of the previous year harvested areas in the previous year, plus the reforested areas in the current year, plus the forest stock from the previous year. From our interviews with SODEFOR, about $15 \%$ of forest-harvested lands become forest again, increasing the forest stock.

Equation (6) stipulated that forestland increases at a rate of $\mathrm{R}_{7}(\mathrm{~T})$ compared to the previous year surface. The intensity of forestland harvested has considerably varied in the past. Indeed, it has been intensive in the period of 1960-1970 with an average yearly increase rate of $16 \%$ before decreasing to $4 \%$ in the years 1971-1980; then it became negative from 1981 to1990. Since 1991, it's been a slow increase in the deforestation due a lack of timber. We estimated the forestland harvest rate at zero from 1996 until the end of our study.

Equations (7) are the conditions of non-negativity. They represent the boundaries allowing the modeling to run in the positive range.

The limit of this model is that it does not include the dynamic of a natural forest due to the lack of scientific data in Côte d'Ivoire. The model also considered as forest a recently reforested area.

\section{Results and Discussions}

\subsection{Comparison of Optimal and Real Area of the Forest Stock}

Optimum surface data obtained from our model relative to scenarios 1, 2, and 3 are compiled in table 1 below. The same data used in figure 2, reveal more the differences between real and optimum sizes of forestland.

Table 1. Evolution of Real and Optimum Forest land areas according to scenarios 1, 2, 3 (x 1000 ha).

\begin{tabular}{|c|c|c|c|c|}
\hline Year & Real Forest area & Optimal Forest area Scenario1 & Optimal Forest area Scenario 2 & Optimal Forest area Scenario 3 \\
\hline 1960 & 10680 & 2800 & 2800 & 2800 \\
\hline 1961 & 10400 & 2821 & 2821 & 2821 \\
\hline 1962 & 10120 & 2845 & 2845 & 2845 \\
\hline 1963 & 9840 & 2874 & 2874 & 2874 \\
\hline 1964 & 9560 & 2906 & 2906 & 2906 \\
\hline 1965 & 9280 & 2944 & 2944 & 2944 \\
\hline 1966 & 8985 & 2989 & 2989 & 2989 \\
\hline 1968 & 8100 & 3099 & 3099 & 3099 \\
\hline 1969 & 7650 & 3168 & 3168 & 3168 \\
\hline 1970 & 7200 & 3248 & 3248 & 3248 \\
\hline 1971 & 6750 & 3340 & 3340 & 3340 \\
\hline 1972 & 6300 & 3448 & 3448 & 3448 \\
\hline 1973 & 5500 & 3560 & 3560 & 3560 \\
\hline 1974 & 5400 & 3676 & 3676 & 3676 \\
\hline 1975 & 5100 & 3797 & 3797 & 3797 \\
\hline 1977 & 4500 & 4053 & 4067 & 4053 \\
\hline 1978 & 4200 & 4189 & 4217 & 4189 \\
\hline
\end{tabular}




\begin{tabular}{|c|c|c|c|c|}
\hline Year & Real Forest area & Optimal Forest area Scenario1 & Optimal Forest area Scenario 2 & Optimal Forest area Scenario 3 \\
\hline 1979 & 3900 & 4979 & 4373 & 4331 \\
\hline 1980 & 3800 & 5126 & 4536 & 4478 \\
\hline 1981 & 3600 & 5279 & 4705 & 4631 \\
\hline 1982 & 3300 & 5438 & 4881 & 4790 \\
\hline 1983 & 3000 & 5589 & 5048 & 4941 \\
\hline 1984 & 2700 & 5733 & 5206 & 5084 \\
\hline 1985 & 2500 & 5869 & 5357 & 5221 \\
\hline 1986 & 2200 & 5999 & 5500 & 5350 \\
\hline 1987 & 2000 & 6122 & 5636 & 5473 \\
\hline 1988 & 1900 & 6239 & 5766 & 5590 \\
\hline 1989 & 1850 & 6350 & 5888 & 5701 \\
\hline 1990 & 1800 & 6456 & 6005 & 5807 \\
\hline 1991 & 1700 & 6556 & 6116 & 5907 \\
\hline 1992 & 1650 & 6651 & 6221 & 6002 \\
\hline 1993 & 1600 & 6747 & 6327 & 6099 \\
\hline 1994 & 1500 & 6844 & 6435 & 6196 \\
\hline 1995 & 1500 & 6943 & 6543 & 6294 \\
\hline 1996 & 1500 & 7042 & 6653 & 6393 \\
\hline 1997 & 1500 & 7142 & 6763 & 6493 \\
\hline 1998 & 1500 & 7242 & 6874 & 6593 \\
\hline 1999 & 1500 & 7342 & 6984 & 6712 \\
\hline 2000 & 1500 & 7442 & 7095 & 6831 \\
\hline 2001 & 1500 & 7542 & 7206 & 6949 \\
\hline 2002 & 1500 & 7642 & 7316 & 7068 \\
\hline 2003 & 1500 & 7742 & 7427 & 7186 \\
\hline 2004 & 1500 & 7842 & 7537 & 7305 \\
\hline 2005 & 1500 & 7943 & 7648 & 7424 \\
\hline 2006 & 1500 & 8043 & 7759 & 7542 \\
\hline 2007 & 1500 & 8143 & 7869 & 7661 \\
\hline 2008 & 1500 & 8243 & 7980 & 7780 \\
\hline 2009 & 1500 & 8343 & 8091 & 7898 \\
\hline 2010 & 1500 & 8343 & 8091 & 7898 \\
\hline 2011 & 1500 & 8343 & 8091 & 7898 \\
\hline 2012 & 1500 & 8343 & 8091 & 7898 \\
\hline 2013 & 1500 & 8343 & 8091 & 7898 \\
\hline 2014 & 1500 & 8343 & 8091 & 7898 \\
\hline 2015 & 1500 & 8343 & 8091 & 7898 \\
\hline 2016 & 1500 & 8343 & 8091 & 7898 \\
\hline
\end{tabular}

Source: Reference [9.] and author's calculation from the model

The results in figure 1 indicated that optimal surfaces from years 1960 to 1978 were considerably less than the real forest stock.

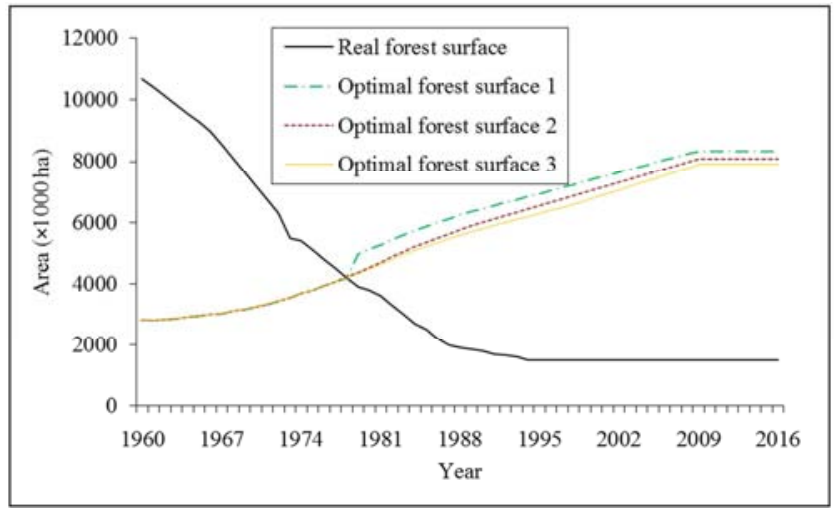

Figure 2. Evolution of Real and Optimum Forest land areas according to scenarios 1, 2, 3 (x 1000 ha).

As can be showed, that optimal solutions (optimal forest area) from 1960 to 2016, for all scenarios, have an increasing trend with a low slope. According to all scenarios, the optimal forest stock starts from $2,800,000$ ha with a slow increase to between $7,898,000$ and 8,343,000 ha.

The optimal forest stock increased slowly each year due to its capitalization (gains value). From 1960 to 1978, the optimal solutions were all identical expressing their total inelasticity with the incomes and social discount rates. After 1978, the optimal solutions seemed to become barely elastic with no significant difference.

Since 1960, the real stock of forest showed a sharp decrease to 1991 before stabilizing until 2016. For that period, the real forest stock decreased from $10,860,000$ ha in 1960 to $1,500,000$ ha in 2016 indicating the sharp decrease caused by demographic changes combined with the basic human needs (agriculture, firewood, charcoal), changes in forest use (use of qualified personnel, new technologies, increasing number of forestry companies), construction of specialized logging seaport (San Pedro), and the international timber price effect.

From 1960 to 1978, even with a sharp decrease, the real forest stock was greater than the optimal forest stock (amount of forest that should be kept, considering its economic value), indicating that the deforestation of forestlands, even without reforestation, was not damageable to the forest environment whatever the 
scenario.

In the other hand, since 1978, figure 1 showed that in all scenarios, the optimal forest stock was greater than the real forest stock. Since these forest entities (optimal and real forest stocks) were divergent in the negative way, we could suggest that the environmental balance has been interrupted because the level of the real forest stock in that period represented a harmful source to the environment. This discrepancy amplified increasingly until 2016. This observation indicated that the forestlands have not been allocated optimally and that their use was not efficient since 1978 (waste or abusive use of the forests). In fact, several factors could play in the explanation of the cause of this rapid disappearance of the real forest stock such as:

- The lack of forestlands planning for the multiple uses. In fact, during the colonial period, the Ivorian forests were so inhospitable that the colonists used them only as a means for financing the colony. Considering this inhospitable situation, the rural colonization of these forests was encouraged. After the country's independence, forestlands were considered as inexhaustible natural resources.

- The failure of the forestry fiscal system to induce good use practices from forest loggers. In fact, the forestry fiscal system should require good use practices during the issuance of harvest permits. In addition, the forestry fiscal system was under evaluated, encouraging overuse; it comprised numerous taxes that created difficulties for their collection by the government agencies due to insufficient funding. The increase of these taxes inclines to encourage overuse of forests as confirmed by reference $[2,12]$.

- The low capacity of the Department in charge of the forestry to work such as the weak qualification of the personnel, lack of new technology equipment for monitoring and control, complex and unrecognized political and institutional maps or framework, bad governance and law level of reforestation as confirmed by reference $[13,14]$.

All these weaknesses have lead to an abusive use of forests $[9,14]$. According to several studies, the forest destruction rate during harvesting was estimated at $4.3 \mathrm{~m}^{3}$ for each $\mathrm{m}^{3}$ harvested [9]. The use of a resource for which the accessibility or extraction cost is lower than the real use cost will lead to waste and unsustainable use of that resource [1, 14]. This affirmation supports on their wastage assumption $[11,12]$. Indeed, the annual financial loss due to the wastage of timber resources was estimated at 200 million USD before the devaluation of the local currency (Franc CFA) in 1994.

The Figure 1 [9] and Figure. 3 [15], Figure 4 [15], below, shows the photographic changes of forest land in Côte d'Ivoire from 1900, 1955, 1988 and 2013. The green colors represent the forest land. The light green in figure 1 represents wooded savanna areas and grassland; The yellow color represent the fallows in Figure 3; The red color in the Figure 4 Represent the amount of forest land that disappeared from 2000 to 2012 according to reference $[9,15]$

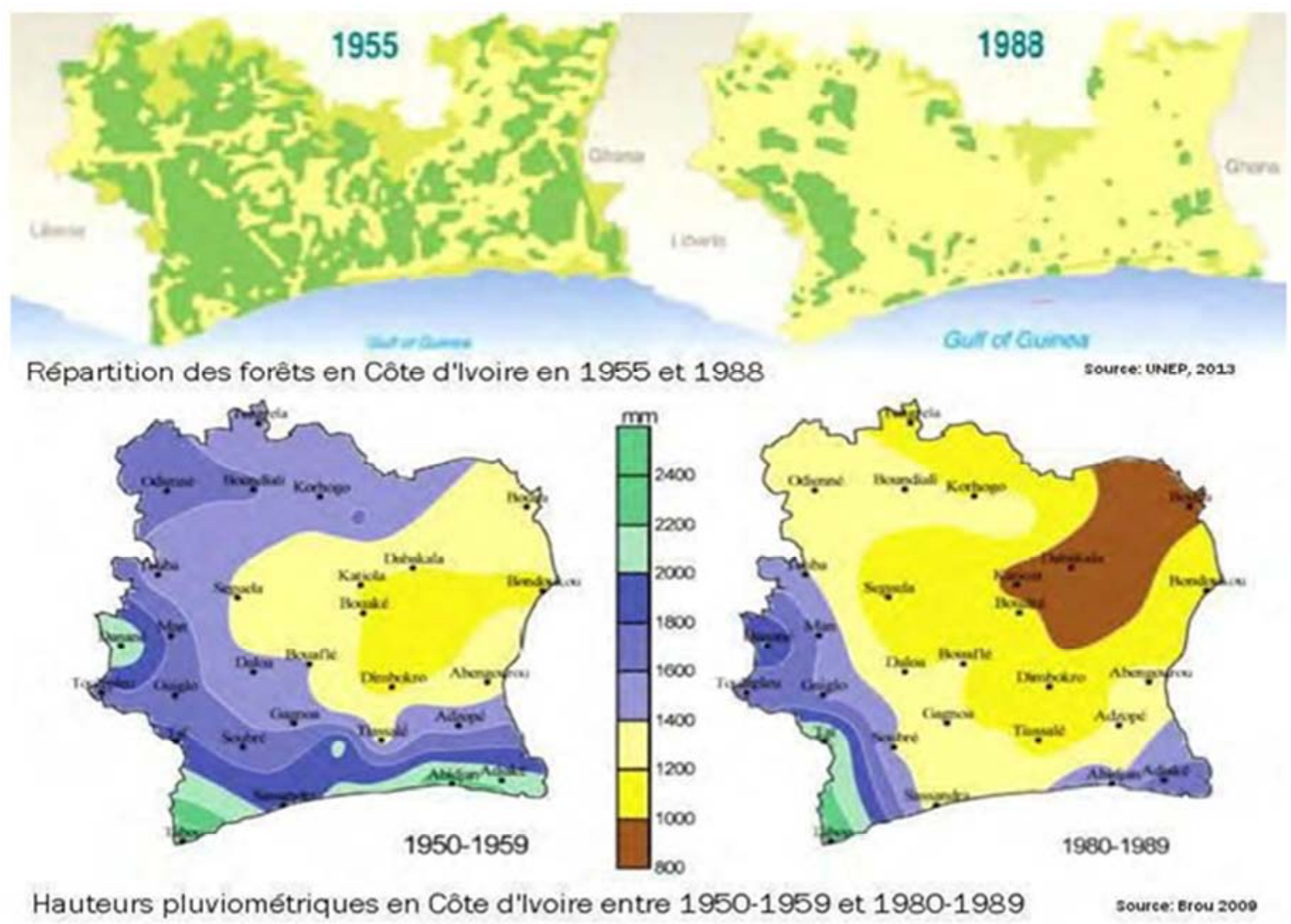

Figure 3. Forest situation in Côte d'Ivoire, 1955 and 1988 [15] 


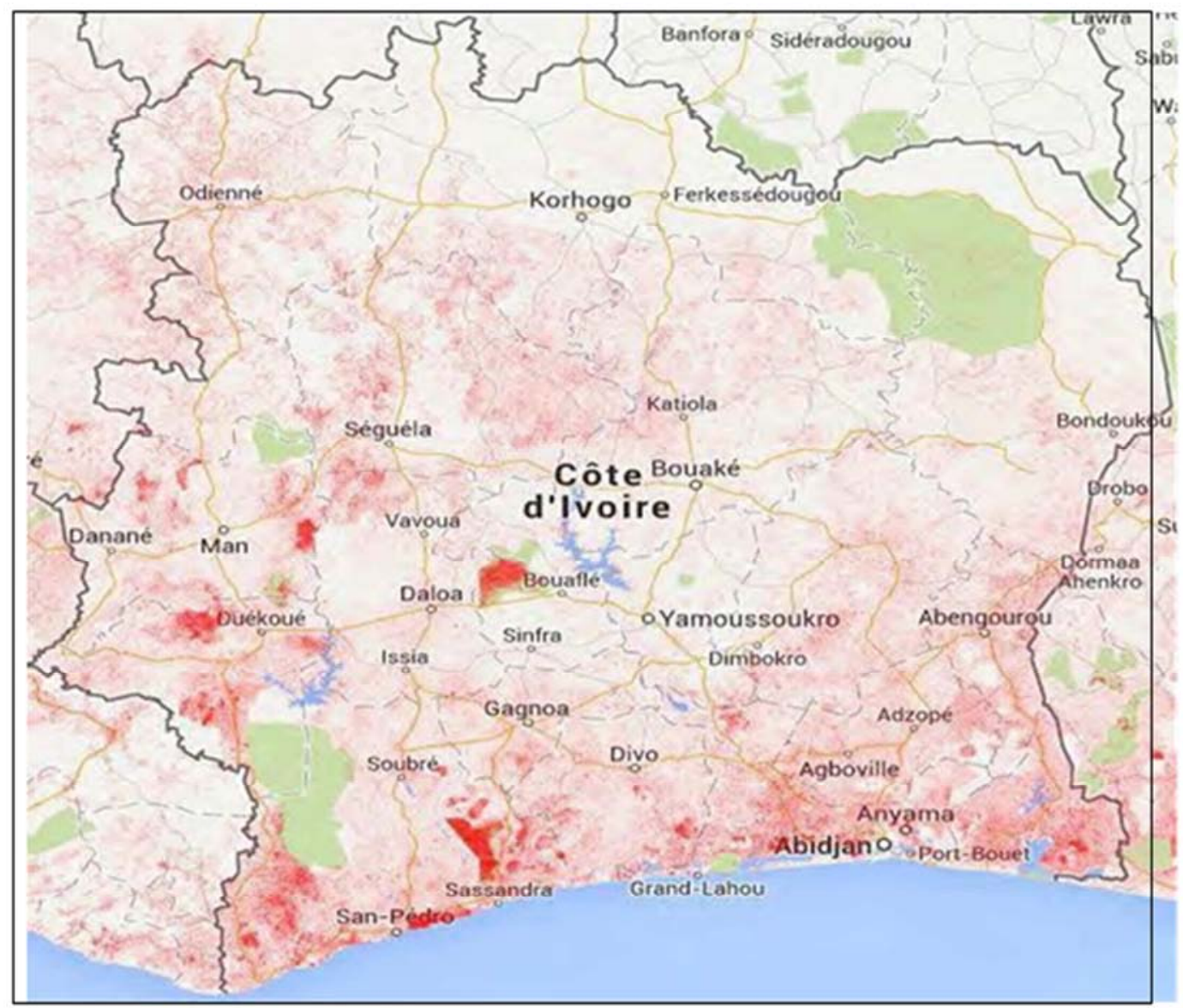

NB: Red color indicate the quantity of forest disappeared from 2000 to 2012.

Figure 4. Forest situation in Côte d'Ivoire, 2013 [15].

\subsection{Comparison of Optimal and Real Area of Reforestation}

The data for this comparison, between real and optimal total reforested areas are compiled in Table 2 and illustrated by Figure 2.

Table 2. Evolution of Real and Optimal according to scenarios reforestation areas (x 1000 ha).

\begin{tabular}{lllll}
\hline Year & Real area Reforested & Optimal area Reforested Scenario 1 & Optimal area Reforested Scenario 2 & Optimal area Reforested Scenario 3 \\
\hline 1960 & 12,835 & -7880 & -7880 & -7880 \\
1961 & 13,685 & -7579 & -7579 & -7579 \\
1962 & 14,56 & -7275 & -7275 & -7275 \\
1963 & 15,46 & -6966 & -6966 & -6966 \\
1964 & 16,41 & -6654 & -6654 & -6654 \\
1965 & 17,46 & -6336 & -6336 & -6336 \\
1966 & 18,61 & -5997 & -5997 & -5997 \\
1967 & 19,81 & -5495 & -5495 & -5495 \\
1968 & 22,06 & -5001 & -5001 & -5001 \\
1969 & 24,31 & -4482 & -4482 & -4482 \\
1970 & 26,56 & -3952 & -3952 & -3952 \\
1971 & 28,81 & -3410 & -3410 & -3410 \\
1972 & 31,06 & -2852 & -2852 & -2852 \\
1973 & 33,31 & -1940 & -1940 \\
1974 & 35,56 & -1940 & -1724 & -1724 \\
1975 & 37,81 & -1303 & -1303 \\
1976 & 40,06 & -1724 & -878 & -878 \\
1977 & 42,31 & -1303 & -433 & -447 \\
1978 & 44,56 & -878 & 17 & -11 \\
1979 & 46,81 & -447 & 473 & 431 \\
1980 & 49,06 & -11 & 736 & 678 \\
1981 & 51,31 & 1079 & 1105 & 1031 \\
\hline
\end{tabular}




\begin{tabular}{|c|c|c|c|c|}
\hline Year & Real area Reforested & Optimal area Reforested Scenario 1 & Optimal area Reforested Scenario 2 & Optimal area Reforested Scenario 3 \\
\hline 1982 & 53,56 & 2138 & 1581 & 1490 \\
\hline 1983 & 57,06 & 2589 & 2048 & 1941 \\
\hline 1984 & 61,56 & 3033 & 2506 & 2384 \\
\hline 1985 & 66,56 & 3369 & 2857 & 2721 \\
\hline 1986 & 71,56 & 3799 & 3300 & 3150 \\
\hline 1987 & 76,56 & 4122 & 3636 & 3473 \\
\hline 1988 & 81,56 & 4339 & 3866 & 3690 \\
\hline 1989 & 86,56 & 4500 & 4038 & 3851 \\
\hline 1990 & 91,56 & 4656 & 4205 & 4007 \\
\hline 1991 & 96,56 & 4856 & 4416 & 4207 \\
\hline 1992 & 101,56 & 5001 & 4571 & 4352 \\
\hline 1993 & 106,56 & 5147 & 4727 & 4499 \\
\hline 1994 & 111,56 & 5294 & 4885 & 4646 \\
\hline 1995 & 116,56 & 5393 & 4993 & 4744 \\
\hline 1996 & 121,56 & 5492 & 5103 & 4843 \\
\hline 1997 & 126,56 & 5592 & 5213 & 4943 \\
\hline 1998 & 131,56 & 5692 & 5324 & 5043 \\
\hline 1999 & 136,56 & 5792 & 5434 & 5162 \\
\hline 2000 & 141,56 & 5892 & 5545 & 5281 \\
\hline 2001 & 146,56 & 5992 & 5656 & 5399 \\
\hline 2002 & 151,56 & 6092 & 5766 & 5518 \\
\hline 2003 & 156,56 & 6192 & 5877 & 5636 \\
\hline 2004 & 161,56 & 6292 & 5987 & 5755 \\
\hline 2005 & 166,56 & 6393 & 6098 & 5874 \\
\hline 2006 & 171,56 & 6493 & 6209 & 5992 \\
\hline 2007 & 176,56 & 6593 & 6319 & 6111 \\
\hline 2008 & 181,56 & 6693 & 6430 & 6230 \\
\hline 2009 & 186,56 & 6793 & 6541 & 6348 \\
\hline 2010 & 191,56 & 6793 & 6541 & 6348 \\
\hline 2011 & 196,56 & 6793 & 6541 & 6348 \\
\hline 2012 & 201,56 & 6793 & 6541 & 6348 \\
\hline 2013 & 206,56 & 6793 & 6541 & 6348 \\
\hline 2014 & 211,56 & 6793 & 6541 & 6348 \\
\hline 2015 & 216,56 & 6793 & 6541 & 6348 \\
\hline 2016 & 221,56 & 6793 & 6541 & 6348 \\
\hline
\end{tabular}

Source: References $[9,17]$ and author's calculation from the model

Figure 2 below indicated that from 1960 to the reference date of 1978, economically the recommended deforestation rate related to forest and agricultural activities should have been at an annual optimal varying roughly from 300,000 to 430,000ha [9]. The optimal reforestation area from 1960 to
1978 did not vary according to the three scenarios, which means that the reforestation was totally inelastic to the financial forest value and the social discount rates. It seems that the annual deforestation rate estimated at 300,000 ha [9] was sustainable before 1978, but not after.

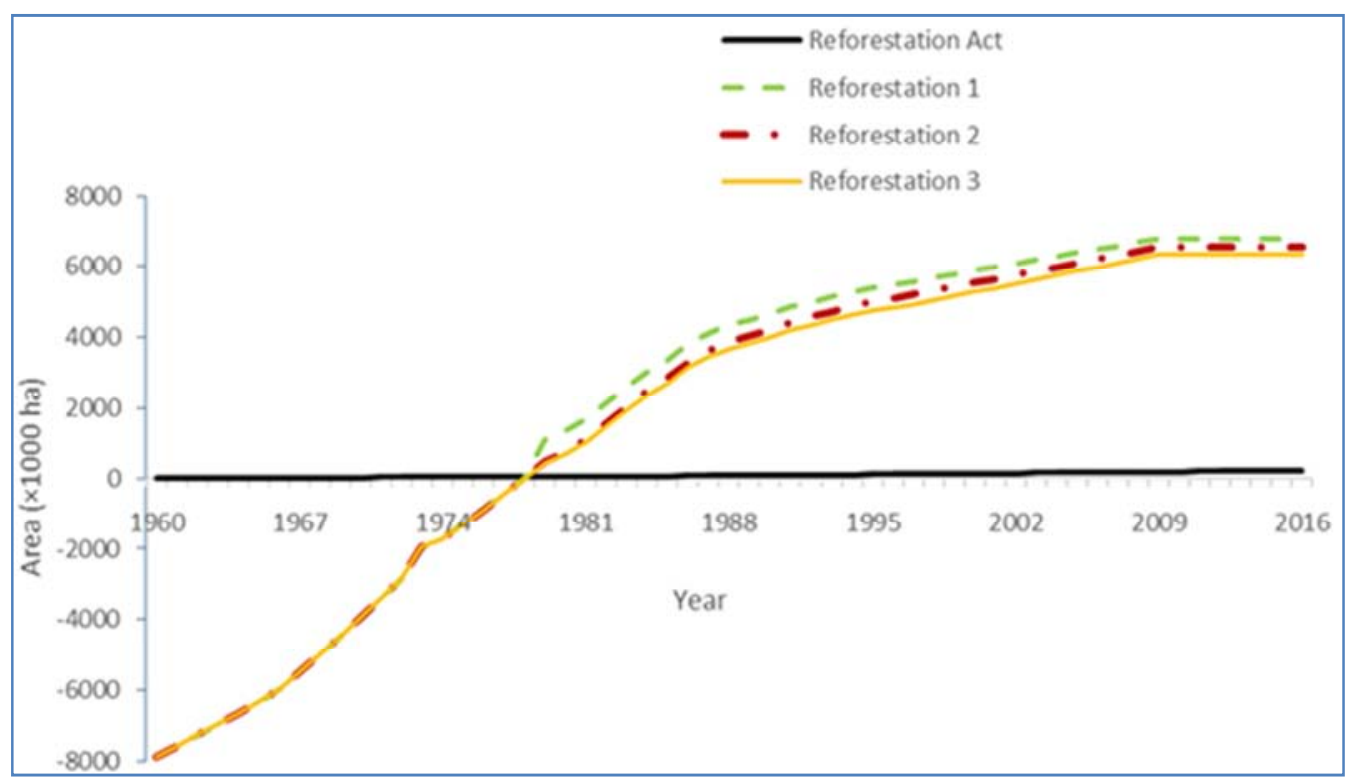

Figure 5. Evolution of Real and Optimal according to scenarios reforestation areas (x 1000 ha). 
As the gap between the optimal forest area and the real forest stock since 1978 increased (Fig. 1), the need for a rapid reforestation of affected areas to reach a balance increased. Consequently, figure 5 indicated that economically the optimal recommended rate of reforestation to reach a balance should be varying roughly from 99000 to 500000 ha/year (Table 3). We also observed that the optimal reforestation rate was inelastic compared to the financial value of the forest and the social discount rates. As well, the cumulative areas to be optimally reforested increased slowly and became constant at $6,348,000$ or $6,793,000$ ha according to the scenarios. The reforestation achievements realized by the government since 1960 varying annually from between 2,000 and 3,500 ha to exceptionally 7,000 ha in 1997 and resulting in the reforestation of 180,000 ha since 1960 [14 ] compared to the annual optimums of reforestation $(99,000$ to $500,000 \mathrm{ha} / \mathrm{ha})$ and the level of optimum reforestation $(6,793,000$ ha) respectively, reflected the insignificance reforestation operations undertaken by the government and subsequently the difficulties to reach an environmental balance.

Regarding the government's failure in the reforestation experiment through Ivorian State Company for Forest Development (SODEFOR), with a high cost of mechanized reforestation (1200 USD to 1600 USD according to this State Company ) that limited reforestation areas to an average of 5,000 ha in contrast to the urgent need to reconstitute the forest stock of the country, the paid community reforestation in a form of civil education seems to be an alternative choice, which has been long used in western Canada. This alternative will encourage participants (villagers and students from primary school, high school, and universities and unemployed people) to join the experiment and will minimize the risk of failure experienced by the mechanized method of SODEFOR. This paid community and civil reforestation, in contrary to the industrial reforestation applied by SODEFOR, should be encouraged. In the past, the reforestation by villagers did not succeed in Côte d'Ivoire because of the following factors:

- The objective of that previous experiment was to encourage farmers to perform reforestation of their own lands, which was not part of their daily duty habits. In addition, these reforestation activities were in conflict with farming activities, which provided quicker income.

- The reforestation by farmers was perceived as a volunteer act and was not paid by the authorities.

Concretely, we could propose the following plan for the community and civil paid reforestation. With our survey indicating that the plant nursery was estimated at 16 cents a plant, by proposing 1 cents the planting of a tree (the equivalent of 18 cents for 250 plants per ha), the cost of the reforestation would be estimated at 75 USD the hectare which covers 35 USD for the salary and 40 USD for plant production at the nursery.

As the optimal cumulative reforestation was estimated at $6,793,000$ ha for all scenarios, a reforestation on a 10-years plan would re-establish the forest stock to its optimal, starting from 2016 at a rate of 680,000 ha/year with an annual reforestation budget of 51 million USD. That budget would represent $0.5 \%$ of the GDP, which is less that the financial loss due to deforestation at 500 million USD representing $6 \%$ of the GDP [14]. Working 22 days each month per person, this reforestation operation should target students and pupils during the school holidays (July to August) and create 30,877 jobs with monthly income of 384 USD per person. The plant production by nurseries should be accomplished mainly by rural primary schools near reforestation sites as experimental gardening work using special technical manuals under the supervision of teachers and Waters and Forests Department agents (Ministry), Participants should include out-of-school people. Each nursery could produce plant to reforest 500 ha which could be estimated at 1360 nursery Centers receiving 20000 USD each.

The economic impact as recommended by references [9, $15,16]$ of such a project will be considerable, as the income perceived by the students would alleviate school fees disbursed by parents at the beginning of each school year and the project being a tool to teach students how to be autonomous. Another advantage would be the migration of unemployed youths in cities towards the countryside at each school break, reducing insecurity and delinquency in cities. In addition, the reforestation activities will allow youths to acquire arboricultural knowledge and the usefulness of the environment. The 20000 USD could cover the often-needed small material expenses such as chalk, rulers, school chairs and tables, notebooks, soccer balls, uniforms, etc. for schools and would represent employment, opportunities for small businesses, a disincentive to youth exodus to big cities, and the consideration for trees and the environment.

Table 3. Annual Real and Optimum reforestation areas according to scenarios 1, 2, 3 (x 1000 ha).

\begin{tabular}{lllll}
\hline Year & Real area Reforested & Optimal area Reforested Scenario 1 & Optimal area Reforested Scenario 2 & Optimal area Reforested Scenario 3 \\
\hline 1960 & 0,835 & -301 & -301 & -301 \\
1961 & 0,85 & -301 & -301 & -301 \\
1962 & 0,875 & -304 & -304 & -304 \\
1963 & 0,9 & -309 & -309 & -309 \\
1964 & 0,95 & -312 & -312 & -312 \\
1965 & 1,05 & -318 & -318 & -318 \\
1966 & 1,15 & -339 & -339 & -339 \\
1967 & 1,2 & -502 & -502 & -502 \\
1968 & 2,25 & -494 & -494 & -494 \\
1969 & 2,25 & -519 & -519 & -519 \\
\hline
\end{tabular}




\begin{tabular}{|c|c|c|c|c|}
\hline Year & Real area Reforested & Optimal area Reforested Scenario 1 & Optimal area Reforested Scenario 2 & Optimal area Reforested Scenario 3 \\
\hline 1970 & 2,25 & -530 & -530 & -530 \\
\hline 1971 & 2,25 & -542 & -542 & -542 \\
\hline 1972 & 2,25 & -558 & -558 & -558 \\
\hline 1973 & 2,25 & -912 & -912 & -912 \\
\hline 1974 & 2,25 & -216 & -216 & -216 \\
\hline 1975 & 2,25 & -421 & -421 & -421 \\
\hline 1976 & 2,25 & -425 & -425 & -425 \\
\hline 1977 & 2,25 & -431 & -431 & -431 \\
\hline 1978 & 2,25 & -11 & 17 & -11 \\
\hline 1979 & 2,25 & 1090 & 456 & 442 \\
\hline 1980 & 2,25 & 247 & 263 & 247 \\
\hline 1981 & 2,25 & 363 & 369 & 353 \\
\hline 1982 & 2,25 & 459 & 476 & 459 \\
\hline 1983 & 3,5 & 451 & 467 & 451 \\
\hline 1984 & 4,5 & 444 & 458 & 443 \\
\hline 1985 & 5 & 336 & 351 & 37 \\
\hline 1986 & 5 & 430 & 443 & 429 \\
\hline 1987 & 5 & 323 & 336 & 323 \\
\hline 1988 & 5 & 217 & 230 & 197 \\
\hline 1989 & 5 & 175 & 172 & 165 \\
\hline 1990 & 5 & 156 & 167 & 156 \\
\hline 1991 & 5 & 200 & 211 & 200 \\
\hline 1992 & 5 & 145 & 155 & 145 \\
\hline 1993 & 5 & 146 & 156 & 147 \\
\hline 1994 & 5 & 147 & 158 & 147 \\
\hline 1995 & 5 & 99 & 108 & 98 \\
\hline 1996 & 5 & 99 & 499 & 99 \\
\hline 1997 & 7 & 100 & 110 & 100 \\
\hline 1998 & 5 & 100 & 111 & 100 \\
\hline 1999 & 5 & 100 & 110 & 119 \\
\hline 2000 & 5 & 100 & 111 & 119 \\
\hline 2001 & 5 & 100 & 111 & 118 \\
\hline 2002 & 5 & 100 & 110 & 119 \\
\hline 2003 & 5 & 100 & 111 & 118 \\
\hline 2004 & 5 & 100 & 10 & 119 \\
\hline 2005 & 5 & 101 & 111 & 119 \\
\hline 2006 & 5 & 100 & 111 & 118 \\
\hline 2007 & 5 & 100 & 110 & 119 \\
\hline 2008 & 5 & 100 & 111 & 119 \\
\hline 2009 & 5 & 100 & 111 & 118 \\
\hline 2010 & 5 & 0 & 0 & 0 \\
\hline 2011 & 5 & 0 & 0 & 0 \\
\hline 2012 & 5 & 0 & 0 & 0 \\
\hline 2013 & 5 & 0 & 0 & 0 \\
\hline 2014 & 5 & 0 & 0 & 0 \\
\hline 2015 & 5 & 0 & 0 & 0 \\
\hline 2016 & 5 & 0 & 0 & 0 \\
\hline
\end{tabular}

Source: Reference [11.] and author's calculation from the model.

\section{Conclusion}

We conclude from this study that:

- The level of real forest stock has decreased drastically from $10,860,000$ in 1960 to $1,500,000$ ha in 2016 while the optimal forest stock, when compared to the financial value and the interest society could confer to it (social discount rates) has increased from $2,800,000$ to 8 , 343,000 ha for the same period. The implementation of our model was used to estimate this value of 8343000 ha, which represents the forest stock necessary to ecological balance of the country. Compare this optimum value of ecological balance, in the current area of forest stock estimated to 1500000 ha nowadays, according to the Ministry of Agriculture, reflects the large deviation from the equilibrium point. This reference value also, illustrates the need for rehabilitation of Ivorian forest capital.

- From 1978, the optimal forest stock was greater than the real forest stock with an increasing gap each year, indicating the period of disruption of the ecological balance. This suggested a desperate need for reforestation, which annual optimal value varied from 99,000 to 500,000 ha, according our model, while the realizable annual reforestation rate, according the World Bank and the Ministry of Waters and Forests [17], varied yearly from 2,000 to 7,000 ha. This new reference which is the optimum value of reforestation, also shows a big gap with the reforestation practices of 
the Government through the State Department for Forest Development (SODEFOR). Indeed SODEFOR reforestation practices are most costly and limits the chances of reaching the balance point. That is why, we proposed an alternative cheaper and faster.

- A paid community reforestation remain the best alternative and will encourage participants (village pupils, students, out of school youths, unemployed people) and minimize risks of failure of this model of reforestation in comparison to the expensive and off state capacity mechanized model used by Ivorian State Company for Forest Development (SODEFOR). For an estimated cost of USD 51 million, according to our estimate, it is possible to reconstitute the forest capital very quickly and easy, so to avoid losing \$500 million every year as environmental cost due to drastic deforestation of the country.

- The determination of these references (optimum forest stock for an ecological equilibrium and optimum reforestation) would help the government adjust its resources for future forest recovery projects, as initiated by the references [15 and 16], in order to significantly revitalize the agriculture and forestry sector, which is the main pillar of the country's economy and the principal jobs provider. One advantage of this strategy will be to considerably decrease the rural exodus.

\section{References}

[1] D. W Pearce, "La gestion des ressources naturelles renouvelables et les incitations économiques". Organisation de coopération et de développement économiques, 1987, pp. 12-88.

[2] FAO, «Le secteur forestier en 2020» Forest Outlook Study for Africa (FOSA), 2012, 20P.

[3] W. Leontief, 1970, "The dynamic inverse" in Carter AP and A. Brody (EDS), Contributions to Input-Output analysis, Amsterdam, North-Holland publishing 17-46 reprinted in Leontief W. 1986, Input-output Economics, New York: Oxford University Press, second edition.

[4] G. R. Walter, Economics of multiple use-Forestry, Journal of environmental management, 1977, PP 345-356.

[5] A. Lugo, R. Schmidt and S. Brown, "Tropical forsts in the Carribbean”, Ambio, pp. 318-324, 1981.
[6] I. Cleroux, and J-M. Salles, "Modélisation économique de la dynamique des forêt: Une revue de littérature", Cahiers d'économie et sociologie rurales, 1996, 41, pp. 92-147.

[7] K. E McConnell. The Quantity of Land in Agriculture. Northeastern Journal of Agriculture and Resource Economics, $1989,(18), 2$.

[8] S. Ehui, and T. Hertel. Deforestation and Agricultural Productivity in the Côte d"Ivoire" American Journal Economics Association, 1989, pp. 702-711.

[9] Ministère de l'Agriculture. Annuaire des Statistiques Agricoles et Forestières", 1900-1989, 1992, 1994, "Plan Directeur du développement agricole 1992-2015" Février 1997, 165 p. «Rapport d'activité" et statistique agricole 1980-2016.

[10] Noufou Coulibaly,. (1998). «Déforestation et Activités Agricoles en Côte d'Ivoire: Recherche d'un nouvel équilibre», $P h D$ thesis, Laval University, Québec, Canada, p. 144.

[11] A. Aké, and B. Dian, "Développement Agricole et Protection de la Forêt: Quel Avenir pour la Forêt Ivoirienne?", Report of the $12^{\text {th }}$ meeting of the Association for the Taxonomical Study of African Tropical Flora (AETFAT), Hamburg, 1990), pp. 169-175.

[12] T. Koné, "Impact du cadre économique sur la gestion de l'environnement". Communication at the national launching seminar for PNAE-CI, 1992.

[13] FMI, Plan National de Développement, Côte d'Ivoire, 2013.

[14] Banque Mondiale, "Revue du secteur agricole, Côte d'Ivoire" Document de travail, Oct. 1994, 107 p." Vers un développement durable sur le plan environnemental en Afrique de l'ouest", Document de travail, janvier 1996, 44 p. "Plan National de Développement de Côte d'Ivoire" 2012.; «Proposition de mesures pour l'Etat de préparation (R-PP), République de Côte d'Ivoire» Fonds de Partenariat pour le Carbone Forestier (FPCF), ONU-REDD, 2013 47P.

[15] Dominique Louppe, «Le secteur forestier en Côte d'Ivoire: Situation actuelle et perspective d'avenir», CIRAD-France, 2013, 15P.

[16] Ministère de l'Environnement et du Développement Durable, «Politique Nationale de l'Environnement», 2011, 81P. Rapport d'activité 2011 à 2016.

[17] Ministère des Eaux et Forêts. "Le Ministère des Eaux et Forêts Genèse, Activités et Perspectives", Rapport Direction du Domaine Forestier et du Reboisement, Décembre 1986, 121 p. "Plan Directeur forestier 1988-2015" Décembre 1988, 87 p. et rapports d'activité 1982-2014; Rapports d'activité SODEFOR 1990-2015. 